Amid Armed Conflict: Perceptions and the Psychological Impact of Covid-19 in Western Libya

\author{
Dr Miriam A. Tresh \\ Department of Psychological and Behavioural Sciences \\ London School of Economics and Political Science
}

\begin{abstract}
Author Note
Data collection was sponsored by LSE Staff Research Fund. No additional funding was received to complete this research. The author declares no conflicts of interest to disclose.

Correspondence concerning this article should be addressed to Miriam Tresh, Department of Psychological and Behavioural Science, London School of Economics and Political Science, London, UK. Email: M.Tresh@Ise.ac.uk
\end{abstract}




\begin{abstract}
Global data on the perceptions and psychological impact of the Covid-19 pandemic suggests the outbreak and restriction measures have had significant negative welfare effects. However, negative psychological symptoms do not emerge with the same intensity for all countries. In western Libya, citizens live under the dual threat of armed conflict and Covid -19 . The situation merits investigation to understand citizens' sensitivity to the pandemic under a pre-existing crisis. This research aims to extend current understanding by examining how coping strategies namely, perceived coping selfefficacy and perceived social support, moderate the effects of the two crises. Furthermore, it intends to explore the additive effect, if any, the outbreak has on the psychological impact of armed conflict. By so doing, it contributes to global data on beliefs, perceptions, and the psychological impact of the pandemic. An online survey in the region during the first surge in Covid-19 cases was completed by 717 respondents. Results show the negative psychological impact of the Covid-19 pandemic is not globally consistent. While citizens of western Libya share the normative belief that their government's response to the outbreak is insufficient, their support for preventative measures diverges negatively from global trends. Moreover, citizens do not have adequate personal coping mechanisms to deal with the impact of armed conflict. These findings are discussed, and recommendations are put forward for action by the government and the international Covid-19 response in Libya. In conclusion, the ongoing civil war has compounded the already dire social and economic conditions, resulting in Covid-19 having little additive effect on citizens' psychological wellbeing. Drawing on social capital, in the form of perceived social support, is thought to buffer the impact of conflict, though the socio-political and economic circumstances may limit this.
\end{abstract}

Key words: Libya, Covid-19, armed conflict, stress, wellbeing, coping, social support 


\section{Amid Armed Conflict: Perceptions and the Psychological Impact of Covid-19 in Western Libya}

The Covid-19 global pandemic has had significant effects on people's psychological wellbeing. The sudden and highly infectious nature of the virus is associated with population-level stress, infection-related fear, pervasive anxiety and impaired subjective wellbeing (Serafini, et al, 2020; Wang, et al, 2020). Since the start of the pandemic governments around the world have adapted different strategies to ensure physical distancing and introduced policies to confine citizens when necessary, including the imposition of lockdowns, curfews, travel bans and the closing of schools, universities and workplaces (Public Health England, 2020; Hale, et al, 2020). Research has sought to understand citizen's beliefs about and the psychological impact of these policies. Early on, the rapid outbreak of the virus and increased media reporting was associated with increased community anxiety (Lima, et al, 2020) and mass quarantine associated with significant negative welfare effects (Brooks et al, 2020; Lades et al, 2020). Limitations on daily life and social interaction are associated with anxiety and depression (Wanng, et al, 2020). These findings seem robust and consistently reported in global data (e.g., Tee, et al, 2020; Grover et al, 2020; Alkhamees, et al, 2020; Rodríguez-Rey, Garrido-Hernansaiz \& Collado, 2020; Rossi, et al, 2020).

Research suggests that these effects can be mitigated by governments providing timely and accurate information and promoting social stability (Wang, et al, 2020). Despite this, a large-scale survey at the onset of the pandemic across 58 countries found many respondents believed that their governments and fellow citizens' response to the pandemic to be insufficient (Fetzer, et al, 2020). Such pessimistic views of citizen and government responses were associated with low psychological wellbeing, while an effective government response potentially reduces pessimism and improves wellbeing (Fetzer, et al, 2020). The aim of the current research is to add to this global understanding by examining beliefs and perception of Covid-19 and restriction measures in western Libya.

There, the onset of the pandemic coincided with escalations in hostilities between various warring factions. Moreover, inadequate healthcare resources and socioeconomic issues have created an environment for the rapid spread of Covid-19 (Da'ar, Haji \& Jradi, 2020). With an already over-stretched and under-resourced healthcare system failing to cope with the civilian casualties (International Crisis Group, 2020), the potential for widespread contagion of Covid-19 was inevitable, albeit delayed as a result of limited international travel amidst economic and sociopolitical instability (Daw, El-Bouzedi \& Ahmed, 2020). By mid-July 2020 the country saw a rapid increase in confirmed cases of Covid-19, reaching 3691 confirmed cases and 80 deaths by 31 July 
$2020^{1}$ (Bredan \& Bakoush, 2020). This initial surge (which coincided with the data collection period for the current research) was particularly prominent in the western and southern regions of the country (Daw, El-Bouzedi \& Ahmed, 2020). Citizens of western Libya therefore live in the presence of two existential threats - armed conflict and Covid-19. This offers a unique perspective from which to investigate the psychological impact and perceptions of the threat of Covid-19 by examine the sensitivity of individuals to the pandemic under a pre-existing crisis.

Research has predominantly focused on understanding the impact of Covid-19 as the immediate threat to individuals, but little is known about perceptions and the psychological impact of the pandemic for individuals already living under another threat. Existing findings show that negative psychological symptoms do not emerge for all countries, highlighting that this seemingly robust observation does not reflect cross-cultural experiences (Atalan, 2020). For citizens of conflict afflicted western Libya the experience of Covid-19 may diverge from the global trend and so warrants investigation. While the pandemic has revealed government shortcomings, aggravated by pre-existing social and economic conditions, it coincides with an already high-stress environment (Christy, 2020; Badi, 2020). As such, whether the threat of mass contagion translates to citizens' perception of Covid-19 as a major concern in their lives over pre-existing armed conflict-related stressors, is less understood and is of interest in the current research. Consequently, the current research seeks to understand the beliefs, perceptions and psychological impact of the pandemic in western Libya, where citizens live under the sustained threat of armed conflict and the rise of confirmed Covid-19 cases.

There is some available data on the effects of Covid-19 in Libya. A cross-sectional survey on the psychological status of frontline healthcare workers found living in a conflict zone, among other socio-demographic factors, to be significantly correlated with heightened depression and anxiety symptoms, along with stigmatisation associated with caring for Covid-19 patients (Elhadi, Msherghi, et al, 2020). Another survey of Libyan medical students found a higher prevalence of anxiety associated with conflict-specific factors, including living status and internal displacement. The associated stress factors of internal displacement include financial stress, the risk of being kidnapped or killed and the risk of homes and belongings being stolen or destroyed. Interestingly, Covid-19 related factors were not associated with heightened anxiety or depression in medical students (Elhadi, Buzreg, et al, 2020). Reports of high psychological stress are equivalent to those reported by

\footnotetext{
${ }^{1}$ At the time of writing (February 2021) there were around 130, 212 confirmed Covid-19 cases in Libya (WHO, 23 Feb 2021, Coronavirus disease dynamic infographic dashboard for Libya)
} 
medical students in Iraq and Syria, who have comparable conflict-related life stressors (see Elhadi, Msherghi, et al, 2020 and Elhadi, Buzreg, et al, 2020 for a discussion).

While frontline health workers and medical students do not represent the general population, the above research provides a premise for the current research by suggesting that conflict-related stressors hold individuals' attentional resources to a greater extent than Covid-19. Therefore, the current research focuses initially on examining citizens' perception and the psychological impact of the two simultaneous crises. Furthermore, the current research extends findings on the perceptions and psychological impact of conflict and Covid-19 in western Libya by examining how coping strategies moderate the effects of the crises on individuals' psychological condition.

\section{Coping Strategies: Coping Self-Efficacy and Perceived Social Support}

Following exposure to armed conflict, individuals experience a loss in their resources. According to Conservation of Resource (COR) theory (Hobfoll, 1989), resources are those objects, personal characteristics, conditions or energies valued by the individual or that serve as a means to attain further resources. Environmental circumstances can lead to depletion of an individual's resources and when stressed an individual will strive to minimise their net loss. Moreover, expending resources to cope with a stressful event is itself stressful, and if the resources employed to cope are greater than the resulting benefits, the individual is likely to show negative coping (Hobfoll, 1989). Studies of trauma exposure show coping self-efficacy (CSE) is an important personal resource to protect individuals from psychological distress and is positively associated with psychological wellbeing (Setti, et al, 2018). Coping self-efficacy is an individual's perceived ability to effectively manage both their personal functioning and external recovery demands in the aftermath of a traumatic event (Benight \& Bandura, 2004). In stress reactions, an individual's belief in their CSE influences evaluations of potential threats and how they are perceived and cognitively processed. Individuals high in CSE believe they can exercise control over threats, which reduces the likelihood of a heightened stress response. Those low in CSE believe the potential threat to be unmanageable, resulting in a heightened stress response (Benight \& Bandura, 2004).

In experimental research where CSE is manipulated (high vs. low CSE), findings show people who are led to believe they have control over aversive events, show a reduced stress response (i.e., lower physiological arousal and less performative impairments) compared to those led to believe they lack personal control (Benight \& Bandura, 2004, also see Hutchinson, Sherman, Martinovic \& Tenenbaum, 2008). Similar observations have been shown in natural experiments. Victims of multiple violence (robbery and theft) experience weaker CSE compared to those exposed to thefts 
only. Those exposed to multiple violence are more likely to perceive a threat to their conditional resources and so experience greater resource depletion and consequently, more serious psychophysical impairments (Setti, et al, 2018). Following a natural disaster, Benight and colleagues (1999) found CSE to be the strongest predictor of general distress and trauma-related distress. Albeit limited, there is some research on the application of COR theory to experiences of armed conflict. One recent study examining COR theory in the context of ongoing armed conflict found resource loss to predict all stress outcomes (depression symptoms, anxiety symptoms, posttraumatic distress and general distress) beyond the contribution of demographics, relocation experiences and daily stressors (Snyder, et al, 2020).

Prolonged conflict exposure in western Libya prior to the Covid-19 pandemic is a significant resource depleting experience. Using a COR framework, those with high exposure to conflict undoubtedly perceive a threat to their resources (object, personal, conditional and energies) and so experience greater resource depletion. Expending resources in an attempt to mitigate the effects of the conflict is stressful and can potentially result in negative coping in relation to the conflict (i.e., low conflict-related CSE). The conflict is unlikely to have left many, if any, resources intact, meaning the Covid-19 pandemic may have little additive effect on citizens' CSE.

Seeking social support is another active coping strategy and one of the most effective means by which people cope with stressful events (Kim, Sherman \& Taylor, 2008). The relationship between stress and perceived social support is well established. For instance, the impact of stress on depression is considerably smaller for those in a high social support group compared to those in a low social support group (Wang, et al, 2014). Hobfoll (1989) argues social support is a resource whereby it provides or facilitates the preservation of valued resources, so is beneficial when it meets situational needs. Setti et al's (2018) study of victims of theft and robbery found those exposed to multiple violence experienced a greater tendency to seek social support than those exposed only to theft. Social capital - the individual or aggregate social resources available through the social environment - is associated with less depression among war-affected youth (Hall, et al, 2014). A review of mental health and psychosocial wellbeing of Syrian refugees affected by armed conflict argues social support can buffer the severity of posttraumatic stress disorder (PTSD) and depression, while those with limited social support networks are vulnerable to psychosocial problems (Hassan, et al, 2016). When exposed to armed conflict, social support likely reflects the availability of interpersonal resources that are responsive to the needs elicited by the trauma event, and acts as a buffer to improve wellbeing (see Cohen \& Wills, 1985 for a review of the buffering hypothesis). 
Citizens of western Libya likely to rely on social support to buffer the psychological effects of conflict. Perceived social support potentially acts as an interpersonal resource that people draw on in response to the conflict to a greater extent than the Covid-19 pandemic. However, this has not been empirically tested and is of interest in the current research.

\section{The Current Research}

The situation in western Libya provides a unique opportunity to investigate people's sensitivity to the pandemic in light of a pre-existing crisis. The research seeks to understand the additive effect, if any, Covid-19 has on the psychological impact of armed conflict. This should contribute to current understanding of beliefs, perceptions, and the psychological impact of the dual crises, by examining how coping strategies (namely, perceived coping self-efficacy and perceived social support) moderate the effects of the two crises. As such, the current research intends to address the following research questions:

1. Do residents of western Libya believe that their fellow citizens and government responded sufficiently to the evolving Covid-19 crisis? And how does their belief relate to their evaluations of Covid-19 as a concern for them?

2. What is the psychological effect of Covid-19 on citizens already living under threat of armed conflict?

3. What is the role of citizens' perceived CSE of the two crises (i.e., conflict and Covid-19)?

4. What is the role of perceived social support as a coping strategy in dealing with the conflict and Covid-19?

In line with Fetzer et al's (2020) observations, it is predicted that citizens of western Libya will display a normative belief that the government and citizens' response to Covid-19 has been insufficient. Give the tumultuous political situation in Libya, it is expected that this belief will be expressed to a greater degree than is seen in global data and will predict individuals' level of concern about the pandemic (i.e., research question 1). In relation to the psychological impact of the two crises, it is predicted that citizens' heightened stress is to a greater extent related to armed conflict than to Covid-19 (i.e., research question 2).

It is predicted that citizens will experience negative conflict-related coping (i.e., low conflictrelated (SE) and this will be a greater predictor of stress than perceived ability to cope with the pandemic (i.e., pandemic-related CSE). Citizens with high levels of conflict exposure will show greater negative coping. Conflict-related coping is expected to moderate the effect of conflict exposure on stress. For people with low conflict-related CSE, conflict exposure will have a greater 
impact on stress than those high in conflict-related CSE. If Covid-19 has little additive effect on CSE and stress, then pandemic-related CSE is not expected to moderate the effect of an individual's concern about the pandemic (i.e., research question 3 ). If citizens rely on social support to cope with the psychological impact of the conflict, it is predicted that perceived social support will be associated with conflict exposure and the inverse of stress. In addition, perceived social support is expected to moderate the effect of conflict exposure on stress, such that those who perceive their social support network to be larger report lower stress in response to conflict exposure than those who perceive their social support network to be small. At the same time, if citizens rely on their perceived social support to cope with the conflict, they will be less supportive of Covid-19 measures designed to curb the outbreak (i.e., research question 4).

\section{Method}

\section{Sample}

A total of 741 respondents started the survey, which was made available online. Of those, responses from 24 participants were removed as they did not meet the eligibility criteria (i.e., they were not 18 years or older and/or residing in western Libya). The final sample of 717 was made up of 427 males, 220 females and eight respondents classified as 'other/prefer not to say' (62 respondents did not report their sex). The mean age of the sample was 37.21 ( $S D=13.42$; age range: $18-78$ ). A summary of the socio-demographic characteristics of the sample are presented in Table 1, excluding missing cases.

Table 1

Relative frequencies of the socio-demographic characteristics of the study sample, excluding missing data

\section{Socio-demographic factors $\quad$ Frequency (proportion as \%)}

$(n=717)$

\begin{tabular}{lrl}
\hline Marital Status & & \\
$\quad$ Married & 328 & $(45.68 \%)$ \\
In a relationship & 31 & $(4.32 \%)$ \\
$\quad$ Divorced & 14 & $(1.95 \%)$ \\
Single & 261 & $(36.35 \%)$ \\
$\quad$ Prefer not to say & 17 & $(2.37 \%)$ \\
& & \\
Education & & \\
$\quad$ Primary/middle/high school & 0 & $(0.0 \%)$ \\
Bachelor's (undergraduate degree) & 410 & $(57.1 \%)$ \\
Master's degree or higher & 87 & $(12.12 \%)$
\end{tabular}

\section{Employment}




$\begin{array}{lrl}\text { Unemployed } & 41 & (5.71 \%) \\ \text { Student } & 105 & (14.62 \%) \\ \text { Occasional worker } & 0 & (0.00 \%) \\ \text { Part-time worker } & 104 & (14.48 \%) \\ \text { Full-time worker } & 226 & (31.48 \%) \\ \text { Self-employed } & 93 & (12.95 \%) \\ \text { Volunteer } & 3 & (3.85 \%) \\ \text { Retired } & 21 & (2.92 \%) \\ \text { No professional work } & 27 & (3.76 \%) \\ & & \\ \text { Income } & & \\ \text { Very low } & 49 & (6.82 \%) \\ \text { Low } & 114 & (15.88 \%) \\ \text { Average } & 405 & (56.4 \%) \\ \text { High } & 82 & (11.42 \%) \\ \text { Very high } & 4 & (0.56 \%) \\ & & \\ \text { Residence } & & \\ \text { Centre of a big city } & 0 & (0.00 \%) \\ \text { Suburbs of a big city } & 181 & (25.21 \%) \\ \text { Medium city } & 84 & (11.7 \%) \\ \text { Town or village } & 48 & (6.69 \%) \\ \text { Isolated home } & 0 & (0.00 \%) \\ \text { Camp } & 1 & (0.14 \%)\end{array}$

\section{Instruments}

The study survey draws on a series of questionnaires and scales, adapted to assess the following constructs: the impact of the crises on individuals and coping, respondents' personal attitudes and perceptions of Covid-19 response measures, and perceived social support. To improve validity, the survey was first translated from English into Arabic and then translated back into English by a second independent translator. The full survey instrument is available at the accompanying OSF repository in English and Arabic. The measures and scales used are outlined in more detail below.

\section{Impact of a crisis}

The Crisis Coping Assessment Questionnaire (CCAQ English version 1.4, Lahlou, et al, 2020) was utilised to assess the impact of the Covid-19 pandemic and conflict on those living in western Libya. The CCAQ is derived from other psychological questionnaires and scales and adapted to be usable in diverse social cultural contexts to assess sources and manifestations of stress, coping mechanisms and support resources during or immediately following a crisis. The CCAQ is a stem survey (i.e., can be used in a whole or part to other surveys) that follows the logic of a clinical interview to assess stress symptoms, coping strategies and the aetiology to better inform crisis response plans and policy making. The questionnaire contains two broad subsections of questions: 
1) an assessment of the situation (i.e., an evaluation of the respondents' socio-demographic situation, agency and environmental affordances), and 2) an assessment of the psychological effects (i.e., stress symptoms and coping strategies). Note that not all questions from the CCAQ were used in the current study - those considered unsuitable for the context and population of interest were removed or adapted (see https://wprn.org/item/413152 for the full survey).

\section{Coping self-efficacy}

To measure coping, the CCAQ's assessment of individuals' self-efficacy, taken from Bosmans et al's (2017) Coping Self-Efficacy Scale, was administered. Respondents were asked the extent to which they sensed the capability to cope ( 1 = completely incapable; $7=$ perfectly capable) with the following experiences: dealing with the impact of the conflict/Covid-19 pandemic, talking about the conflict/Covid-19 pandemic, dealing with frightening images or dreams about the conflict/Covid-19 pandemic, being optimistic since the start of the conflict/Covid-19 pandemic, seeking help from others because of the conflict/Covid-19 pandemic.

\section{Personal attitudes and perceptions of Covid-19 measures}

To assess respondents' personal attitudes and perceptions of responses to the Covid-19, the study drew on three subsets of questions taken from Fetzer, et al's (2020) examination of global behaviours and perceptions of the pandemic response. These subsets were: 1) four questions assessing the respondent's personal attitudes about the Covid-19 measures, referred to as firstorder beliefs, 2) four questions assessing respondent's perception of others' beliefs about the Covid19 measures, referred to as second-order beliefs, and 3) five questions assessment the respondent's perceptions of the government and public response and efficacy.

\section{Perceived social support}

To assess the respondent's support network and examine the potential role of perceived social support in moderating the impact of conflict and Covid-19 on experienced stress and coping strategies, Blake and McKay's (1986) single-item measure of social support was adapted. The original item asked participants "How many people do you have near that you can readily count on for real help in times of trouble or difficulty, such as watcher over children or pets, give ride to hospital or store or help if you are sick?" with possible responses options being 0, 1, 2-5, 6-9 and 10 or more. In the current study, this item was adapted to read "'How many people do you have near that you can readily count on for real help in times of trouble or difficulty?" with the same response options, to better reflect the study context. 


\section{Procedure}

The survey was run online using Qualtrics Survey Software and took approximately 20min to complete. At the start of the survey, respondents were asked to choose their preferred language English or Arabic. To be eligible to complete the survey, participants had to be 18 years or older and living in the capital of Libya, Tripoli, or surrounding western regions of the country. To incentivise participation, respondents were asked to leave their contact email address or phone number at the end of the survey to be entered into a draw for the chance to win a $f 50$ Amazon voucher.

A call to participate and link to the survey were launched initially in English on social media (Twitter, Facebook) on June 5, 2020. The survey was further disseminated using a snowball sampling technique and booster posts on social media sites (Twitter and Facebook) in English and Arabic. On July 3, 2020 a Facebook ad campaign was launched in English and Arabic, geographically targeted at those living in western areas of Libya (defined as Tripoli $+70 \mathrm{~km}$ radius). Data collection took place between June 5, 2020 and July 19, 2020. It should be noted that the sample is not viewed as representative as it is possible that individuals more concerned about the Covid-19 pandemic were disproportionately more likely to complete and share the survey (as discussed by Fetzer, et al, 2020). Details of the survey dissemination and the full survey instrument (shared in English and Arabic) are available at the accompanying OSF repository.

\section{Results}

\section{Data pre-processing}

All data pre-processing and analysis was conducted using $\mathrm{R}$ (version 3.6.1). Visual inspection of the dataset was conducted to identify the proportion of missing observations, and the mechanisms and pattern of missing data to determine the appropriate principled missing data method for inferential analyses (see Dong \& Peng, 2013 for a review). A relative frequency analysis revealed approximately $23 \%$ of observations were missing from the final dataset and visual inspection identified a monotone pattern of missingness. The majority of missingness likely reflected drop-out rates and consequently classified as missing at random (MAR). This type of missing data does not introduce bias into the analysis, though the reduced sample size can inflate standard errors. A power analysis with a $95 \%$ confidence interval prior to data collection determined a minimum sample size of 385 respondents. As such, the multiple imputation method (MI) was used. The method uses the distribution of the observed data to make multiple estimates of the value of the data points, accounting for the uncertainty of the true value (Dong \& Peng, 2013; Bennett, 2001). MI was conducted using the 'mice' (multiple imputation by chained equation) package in $R$ 
(van Buuren \& Groothuis-Oudshoorn, 2011) with 20 imputation iterations and automatic pooling. Following imputation of the data to address missingness, the distribution of variables was inspected. Those variables with non-normal distributions were subject to a log transformation prior to analysis. The following analyses were performed on imputed data and are presented in order of the research questions stated above.

\section{Personal beliefs about Covid-19 measures and perceptions of the public and government response}

While $90 \%$ of respondents believed social gatherings should be cancelled in response to the pandemic, they estimated on average that only $46 \%$ of their fellow residents thought the same $-a$ 44 percentage point gap. Ninety-three percent of respondents believed people should avoid handshaking, yet on average only $47 \%$ of people in the country supported the same measure (a 46 percentage point gap). Interestingly, $57 \%$ believed non-essential stores should be closed in response to the pandemic and $54 \%$ believed a general curfew should be imposed. In contrast, respondents believed that $36 \%$ of their fellow residents' support the closure of stores and $33 \%$ are in favour of curfews (21 percentage point gap in both instances). First- and second-order beliefs are presented in Figure 1. When asked directly about Libya's public reaction to the pandemic, of those who responded, $72 \%$ believed it to be insufficient (i.e., somewhat insufficient or not at all sufficient).

Respondents' own beliefs and their perceptions of their fellow citizens were entered into a multivariate regression model to determine the extent to which each predicted respondents' level of concern about the covid-19 pandemic. An index of first-order beliefs (FOB) was calculated by summing across the four binary beliefs: a) social gatherings should be cancelled, b) people should stop shaking hands, c) all non-essential stores should be closed, and d) a general curfew should be imposed. Each belief was recoded such that disagreement was coded as 0 and agreement coded as 1. A single index of second-order beliefs (SOB) was calculated by summing across respondents' perceptions of their fellow citizens' beliefs in the same four measures. Respondents rated the extent to which they considered Covid-19 a current cause for concern on a 7-point Likert scale (1 = not a concern at all; 7 = a very big concern). To standardise the measures of first- and second-order beliefs, all variables were expressed as a z-score transformation. Analyses revealed that respondents' own beliefs predicted their evaluation of the outbreak as a cause for concern in their lives $(p<.001 ; \mathrm{Cl}=0.2,0.04)$, while their perception of others' beliefs did not $(p=.24)$, as shown in Table 2 (Panel A). The regression model indicated first-order beliefs explained $5 \%$ of variance in pandemic-related concern [Multiple $\mathrm{R}^{2}=.046, \mathrm{~F}(2,714)=18.31, p<.001$ ]. It is important to consider the low explanatory power of the model as it suggests the outcome is predicted by other factors not captured in the current study. 
The descriptive results suggest citizens of western Libya do not hold normative beliefs about Covid-19 measures to the same degree as seen in global data. Respondents also underestimated to a greater extent, their fellow citizens' support for measures and a greater majority believed the Libyan public response to be insufficient. Moreover, respondents' evaluations of the pandemic as a substantiative cause for concern was predicted by their personal attitudes towards Covid-19 measures, but not their estimates of others' beliefs about the measures.

\section{Figure 1}

Descriptive statistics of respondents' own beliefs and perceptions of fellow citizens' reaction to Covid19 measures.

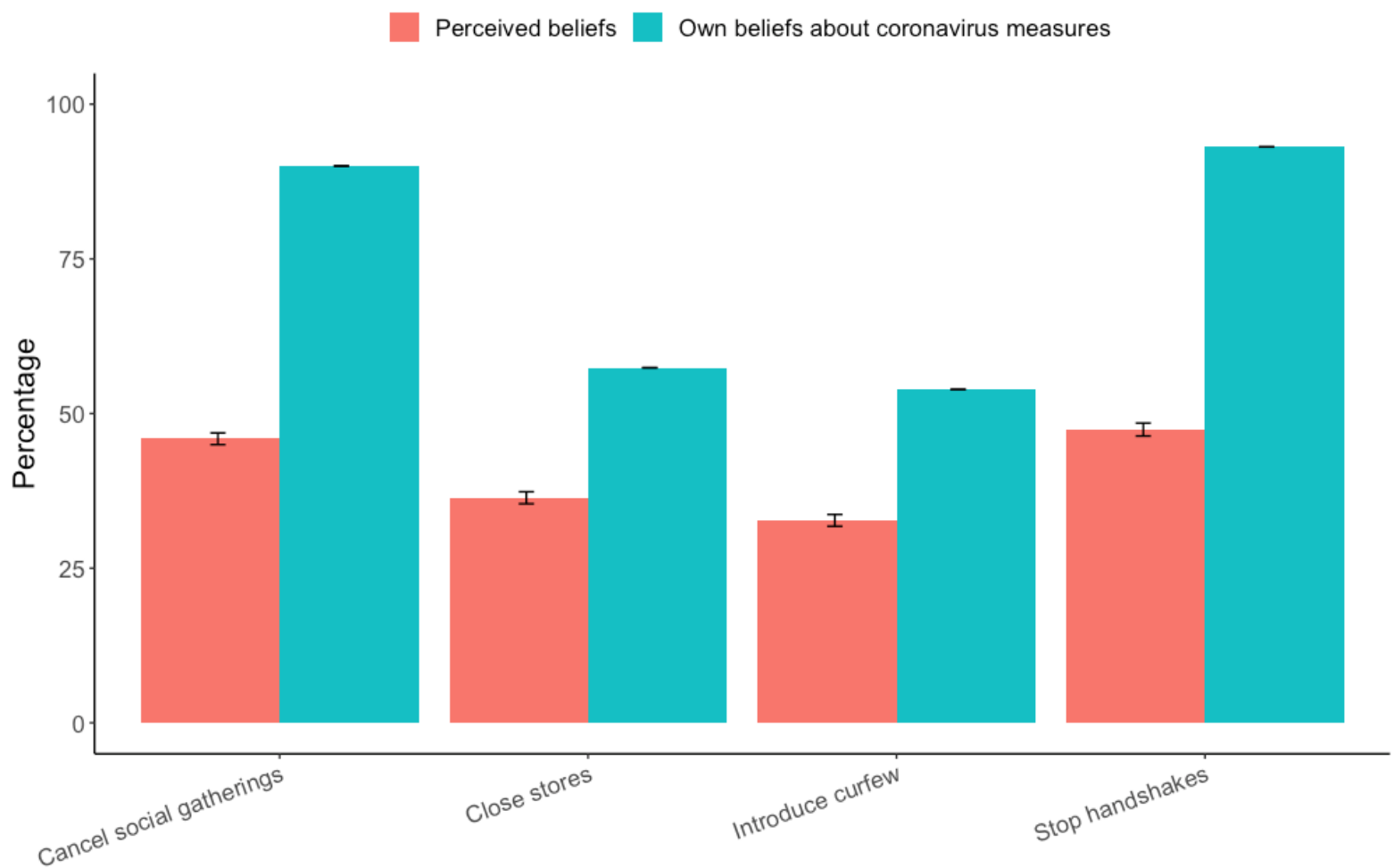

Coronavirus measures

Respondents also held pessimistic beliefs about the governing authority. Eighty-one percent of respondents believed the government response to the outbreak was insufficient (i.e., somewhat insufficient or not at all sufficient). In addition, $68 \%$ of respondents distrusted the government to take care of citizens and $55 \%$ believed the government had not been truthful about Covid-19. To determine the extent to which the insufficient government and public response related to respondents' evaluations of Covid-19 as a cause for concern, perceptions of the public's reaction, perceptions of the government response, government trustworthiness and the truthfulness of the government were entered as predictors into a multivariate regression analysis. The model showed 
that the insufficient government response to the pandemic was a significant predictor of respondents' belief that Covid-19 is a major concern in their lives $(p<.001 ; \mathrm{Cl}=0.37,0.47)$. Distrust in the government's ability to take care of citizens $(p=.08)$, perceptions of the insufficient public response $(p=.26)$ nor the belief that the government has not been factually truthful about the pandemic $(p=.88)$ reached statistical significance, as shown in Table 2 (Panel B). It is important to note that the model account for only $4 \%$ of variation in concern about Covid-19 [Multi $R^{2}=.038, F(4$, $664)=5.06, p<.001]$, suggesting the outcome is predicted by other factors not captured in the current study.

Table 2

Parameter estimates for predictors of concern about the Covid-19 pandemic

\begin{tabular}{llll}
\hline & Est. & $S E$ & $t$ value \\
\hline A: First- and second-order beliefs in Covid-19 measures & & & \\
$\quad$ Intercept & 0.46 & 0.08 & 6.03 \\
FOB Index & 0.25 & 0.04 & $5.92^{* * *}$ \\
SOB Index & -0.02 & 0.03 & -0.53 \\
& & & \\
B: Perceptions of public and government reaction to Covid- & & & \\
19 & & & \\
Intercept & 0.42 & 0.03 & 16.36 \\
Perception of insufficient government response & 0.18 & 0.05 & $3.31^{* * *}$ \\
Lack of trust in government & -0.10 & 0.05 & -1.82 \\
Perception that the government is untruthful & 0.04 & 0.06 & 0.73 \\
Perception of insufficient public response & 0.10 & 0.06 & 1.82 \\
\hline
\end{tabular}

${ }^{* *} p<.01 ; * * *<.001$

In sum, the descriptive results illustrate that a substantial portion of respondents believed that the response to the pandemic by citizens and the government in western Libya was insufficient. A considerably larger proportion of respondents believed the government response to be insufficient $(81 \%)$, did not trusted the government to take care of citizens $(68 \%)$ and believed the government has not been truthful about Covid-19 (55\%). Nonetheless, it was the perception of an insufficient government response driving concern about the pandemic. However, it is important to recognise the limited explanatory power of the model, in view of the broader socio-political factors that could bear on respondents' concern about the pandemic and heighten perceptions of an insufficient government response. These factors are considered in the general discussion. 


\section{Stress and coping self-efficacy of the study population}

The CCAQ's (Lahlou, et al, 2020) assessment of the psychological effects (i.e., stress symptoms and coping strategies) of the crises asked individuals to indicate the frequency with which they experience a range of physical, emotional and behavioural stress symptoms (i.e., never, sometimes or every day). Emotional symptoms were the most common manifestation of stress, with $25.4 \%$ of emotional stress symptoms reported on a daily basis, $55.5 \%$ experienced sometimes and $19.1 \%$ never experienced. For behavioural symptoms, $15.7 \%$ were experienced daily, $48.7 \%$ experienced sometimes and $35.6 \%$ never experienced. Physical symptoms were the least experienced manifestation of stress, with $46.9 \%$ never experienced, $43.3 \%$ experienced sometimes and $9.7 \%$ experienced every day. Figure 2 illustrates the proportion of stress symptoms reported by respondents on a daily basis, sometimes or never, together with a breakdown of the proportion of stress-related behaviours.

In terms of emotional responses to stress, between 23 and $28 \%$ of respondents reported experiencing anxiety (28\%), low energy (27\%), irritability (23\%), difficulty concentrating (21\%), tension (28\%) and fatigue (24\%) on a daily basis. In terms of behavioural responses to stress, between 21 and 33\% of respondents reported daily struggles with work (33\%) and feelings of anger (21\%) and loneliness (21\%), while respondents reported problems with sleeping $(21 \%)$ and feelings of restlessness (20\%) as daily physical responses to stress. 


\section{Figure 2}

Proportion of behavioural, emotional and physical symptoms of stress reported as experience by respondents on a daily basis (i.e., everyday), sometimes or never (left). Proportion of respondents reporting behavioural, emotional and physical symptoms of stress reported as experience by respondents on a daily basis (i.e., everyday), sometimes or never (right).
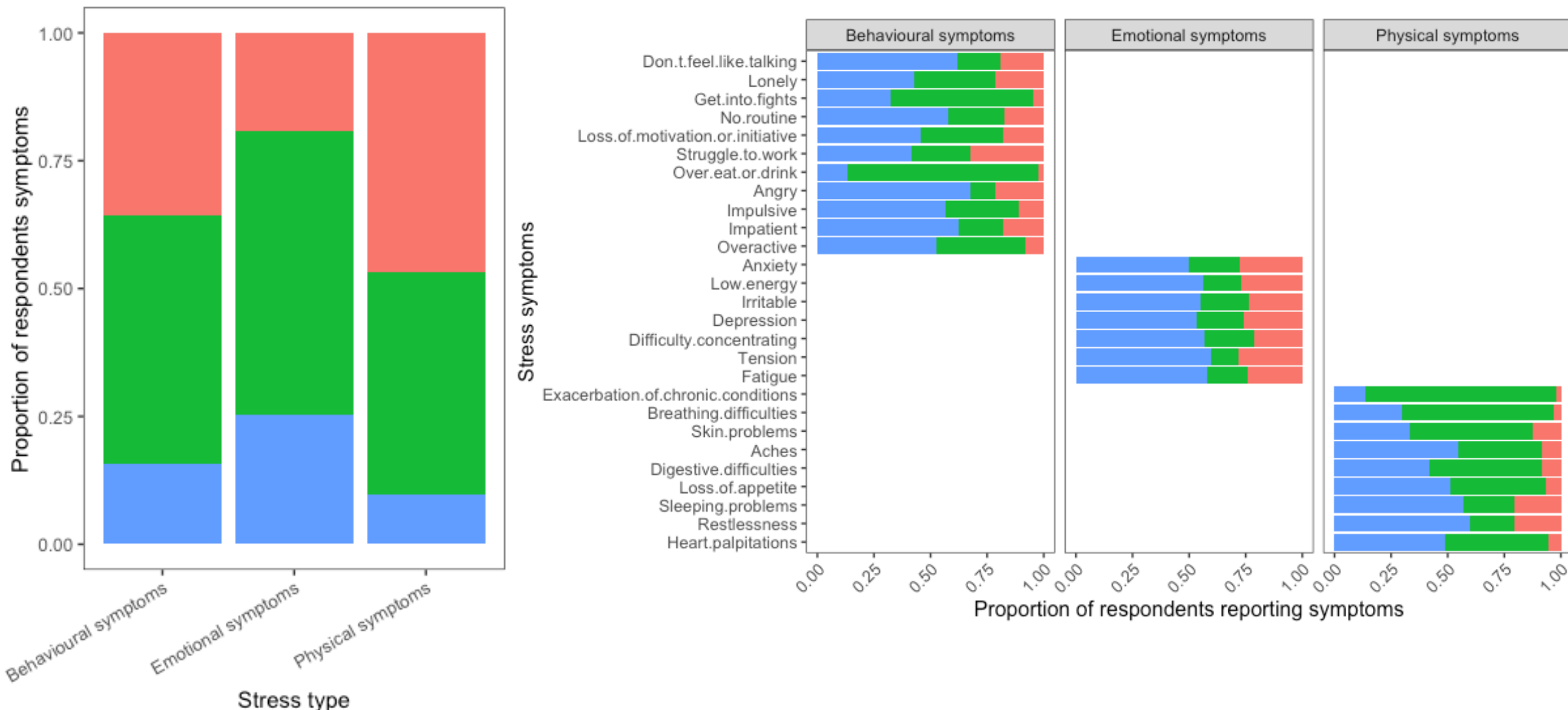

Symptom prevalence

Every day

Never

Sometimes 
To capture respondents' sense of being able to cope with the conflict, a composite variable was created by summing the z-scores of the five conflict-sensitive coping self-efficacy (CSE) items (i.e., capability to deal with the impact of conflict, to deal with frightening images/dreams, to talk about the conflict, to be optimistic, and to seek help from others). This method was also used to create a second composite variable to capture respondents' ability to cope with the Covid-19 pandemic using the five coronavirus-sensitive coping items (i.e., capability to deal with the impact of the pandemic, to deal with frightening images/dreams, to talk about the pandemic, to be optimistic, and to seek help from others). Two additional items capturing general coping (being emotionally strong and being able to carry on with everyday life) were measured. This resulted in a total of four experiences of coping, each expressed as z-score transformations. Individuals' overall stress was calculated as a composite by summing the z-scores of the three stress symptoms components (physical, emotional and behavioural stress symptoms. Stress was expressed as a z-score transformation.

Respondents' sense of being able to cope with the four experiences outlined above were entered into a multivariate regression model to determine the extent to which each predict respondents' level of overall stress. The regression model indicated that a combination of reduced sense of being able to carry on with everyday life, reduced emotional strength and a sense of being incapable of coping with the conflict explained $12 \%$ of variance in overall stress [Multiple $R^{2}=.12$, $F(4,491)=17.32, p<.001]$. As shown in Table 3, reduced capacity to deal with everyday life predicted increased stress $(\mathrm{Cl}=-0.72,-0.22)$, as did an inability to be emotionally strong $(\mathrm{Cl}=-0.57$, 0.07), and negative conflict-related coping $(\mathrm{Cl}=-0.22,-0.20)$. Being able to cope with the Covid-19 pandemic did not predict stress $(p=.09)$. This suggests population stress is the result of prolonged conflict exposure affecting the ability to continue with daily life and remain emotionally strong. The emergence of the Covid-19 pandemic has little additive effect on populations stress. Again however, it is important to note the small variance explained by these factors, which suggests complexity in respondents experience of conflict-related stress, which will be considered in the general discussion.

\section{Table 3}

Parameter estimates for perceived CSE as predictors of stress

\begin{tabular}{llll}
\hline & Est. & $S E$ & $t$ value \\
\hline Capability to cope with experience & & & \\
Intercept & -0.06 & 0.10 & -0.57 \\
Coping with the conflict & -0.15 & 0.05 & $-2.84^{* *}$ \\
Coping with Covid-19 & 0.06 & 0.05 & 1.19 \\
Carrying on with everyday life & -0.37 & 0.12 & $-3.16^{* * *}$ \\
Being emotionally strong & -0.29 & 0.13 & $-2.25^{*}$ \\
\hline
\end{tabular}

$* p<.05 ; * * p<.01 ; * * * p<.001$. 
In sum, the descriptive results illustrate a high level of stress experienced by respondents. To some degree all symptoms of stress - behavioural, emotional and physical - are experienced on a daily basis. Emotional symptoms are the most prevalent, followed by behavioural symptoms and physical symptoms were the least prevalent. An inability to be emotionally strong contributes to respondents' stress, alongside an inability to carry on with everyday life and negative conflict-related coping. Respondents' perceived ability to cope with Covid-19 did not predict stress. Taken together, this suggests the high levels of stress are related to the conflict and resulting socio-political and economic consequences on daily life, and not the pandemic.

\section{Coping self-efficacy as a moderator in the relation between conflict exposure/pandemic concern and stress}

To capture individuals' conflict exposure a composite variable was created by summing the z-scores of four conflict-sensitive items: access to resources, concern about the conflict, conflict loss (i.e., whether respondents reported losing a family or friend to the conflict) and conflict-specific fears. Correlational analysis revealed the variables to be highly statistically related (all $p^{\prime} s<.001$ ) and together were believed to conceptually reflect an individual's exposure to the conflict (original variables are explained in detail in the accompanying data documentation). Conflict exposure was expressed as a z-score transformation (i.e., sum of the z-scores of the composite components).

As expected, correlation analysis revealed a significant relationship between conflict exposure and stress $[r=0.51, S E=.03, p<.001]$. Respondents with higher exposure to conflict experience higher levels of overall stress, as well as higher physical $[r=0.44, S E=.03, p<.001]$, emotional $[r=0.41, S E=.03, p<.001]$ and behavioural $[r=0.37, S E=.04, S E=.04, p<.001]$ stress symptoms. Analysis also revealed a significant relationship between conflict exposure and negative conflict-related CSE $[r=-0.18, S E=.05, p<.001]$, though this correlation was small.

A moderation analysis was conducted to examine whether the relationship between conflict exposure and stress was moderated by conflict-related CSE. For all moderation analyses the standardised variables were first centred and an interaction term between the predictor and moderator was created. Then a multiple regression was performed with stress as the outcome and conflict exposure, controlling for conflicted-related CSE, and their interaction term as the predictors. In this model (Multi $R^{2}=.27$ ), the interaction of conflict exposure and conflict-related CSE did not reach statistical significance $(p=.40)$. The main effects of conflict exposure and CSE were significant ( $p^{\prime} s<.001$ ), with heighted conflict exposure and negative conflict-related coping independently related to increased overall stress. It is important to consider the small size of the relationship between conflict-related CSE and stress, as this suggests the negative impact of conflict exposure 
considerably outweighs any benefit of perceived CSE. Taken together, this suggests the impact of conflict exposure-induced stress does not differ as a function of individuals' perceived CSE.

Turning to individuals' CSE for Covid-19, pandemic-related CSE did not correlated with individuals' concern about Covid-19 $[r=0-.06, S E=.05, p=.18]$. However, concern was significantly related to heightened stress $[r=0.11, S E=.04, p<.01]$ and so too was a perceived inability to cope with the pandemic $[r=-0.16, S E=.04, p=<.001]$. A multiple regression model was performed to examine whether the relationship between concern about the Covid-19 and stress was moderated by pandemic-related CSE. In this model (Multi $R^{2}=.04$ ), the interaction between concern about the pandemic and Covid-19-related CSE did not reach statistical significance. The main effects of pandemic concern and CSE were significant, such that the former was independently associated with heightened stress and the latter independently associated with a reduction in stress. However, it is important to recognise the small size of these associations.

Table 4

Parameter estimates for predictors of stress in a moderation analysis

\begin{tabular}{llll}
\hline & Est. & $S E$ & $t$ value \\
\hline $\begin{array}{l}\text { The effect of conflict exposure on stress, } \\
\text { moderated by conflict-related coping }\end{array}$ & & & \\
$\quad$ Intercept & -0.04 & 0.09 & -0.48 \\
$\quad$ Conflict exposure & 0.46 & 0.04 & $12.5^{* * *}$ \\
$\quad$ Conflict coping & -0.11 & 0.03 & $-4.50^{* * *}$ \\
$\quad$ Conflict exposure X Conflict coping & -0.01 & 0.01 & 0.84 \\
\hline The effect of pandemic concern on stress, & & & \\
moderated by Covid-19-related coping & & & \\
$\quad$ Intercept & -0.04 & 0.10 & -0.44 \\
$\quad$ Pandemic concern & 0.26 & 0.10 & $2.66^{*}$ \\
$\quad$ Pandemic coping & -0.10 & 0.03 & $-3.57^{* * *}$ \\
Pandemic concern X Pandemic coping & -0.02 & 0.02 & -0.96 \\
\hline
\end{tabular}

${ }^{*} p<.05 ;{ }^{* *} p<.01 ;{ }^{* * *} p<.001$.

In sum, the findings reveal conflict exposure as the largest independent contributor to respondents' overall stress. While conflict-related CSE was independently associated with a reduction in overall stress, the effect was small and potentially masked by the psychological impact of conflict exposure. Conflict-related CSE did not moderate the effect of conflict exposure on stress. Similarly, pandemic-related CSE did not moderate the effect of concerns about Covid-19 on stress and while there were independent associations between concern and CSE on stress, these were relatively small 


\section{Perceived social support as a moderator in the relation between conflict exposure/pandemic concern and stress}

Perceived social support was captured by assigning each categorical scale a numerical value, expressed as a standardised z-score. Respondents' perceived access to a social support network was significantly related to the inverse of stress $[r=-0.14, S E=.05, p<.01]$. Those respondents who reported having access to a larger social support network reported fewer overall stress symptoms. Further analysis revealed social support was significant correlated with reduced physical $[r=-0.11$, $S E=.05, p<.05]$, emotional $[r=-0.15, S E=.06, p<.05]$ and behavioural $[r=-0.08, S E=.04, p<.05]$ stress symptoms, though these associated were small. Interestingly, those with higher exposure to conflict reported smaller social support networks $[r=-0.18, S E=.05, p<.01]$. As reported above, conflict exposure was correlated with overall stress (see above).

A moderation analysis was conducted to test whether perceived social support dampens the effects of conflict exposure on stress. A multiple regression model was specified with stress as the outcome and conflict exposure, controlling for perceived social support, and their interaction term as the predictor variables. In this model (Multi $R^{2}=.30$ ) the interaction of conflict exposure and perceived social support was non-significant $(p=.07)$. The main effect of conflict exposure was significant, with conflict exposure positively associated with stress, as previously stated. The main effect of perceived social support did not reach statistical significance $(p=.1)$. As expected, no statistically significant relationship was observed between access to social support and concern about Covid-19 [ $r=.04, S E=.04, p=.34]$. Adding to the findings above, conflict exposure is the major contributor to overall stress and conflict-induced stress does not differ as a function of perceived social support. This suggests perceived social support does not effectively mitigate the negative psychological consequences of conflict.

Conflict exposure was related to Covid-19 concern $[r=0.11, S E=.05, p<.05]$, but not firstorder beliefs about Covid-19 [ $r=-.004, S E=.04, p=.33]$ or perceptions of others' beliefs about Covid-19 measures $[r=-0.01, S E=.04, p=.74]$. As expected, pandemic concern was significantly associated with support for Covid-19 measures $[r=0.28, S E=.05, p<.001]$ and the belief that others' support Covid-19 measures $[r=0.18, S E=.04, p<.001]$. Those who express concern about the pandemic support the implementation of measures to curb the outbreak and believe others share the same view.

A moderation analysis was conducted to test whether conflict exposure reduces the effects of pandemic concern on support for Covid-19 measures (i.e., first-order beliefs). Pandemic concern, controlling for conflict exposure, and their interaction were entered as predictors of support for 
Covid-19 measures. In the model (Multi $R^{2}=.083$ ) the interaction term did not reach statistical significance $(p=.72)$. The main effect of pandemic concern was significant, as was the main effect of conflict exposure. Concern about Covid-19 was associated with first-order beliefs, independent of the effect of conflict exposure on reducing support for measures. Parameter effects are presented in Table 5.

Table 5

Parameter estimates for predictors of stress and support for Covid-19 measures

\begin{tabular}{llll}
\hline & Est. & $S E$ & $t$ value \\
\hline $\begin{array}{l}\text { A: The effect of conflict exposure on stress, } \\
\text { moderated by perceived social support }\end{array}$ & & & \\
$\quad$ Intercept & -0.02 & 0.10 & -0.23 \\
$\quad$ Conflict exposure & 0.57 & 0.04 & $13.90^{* * *}$ \\
$\quad$ Perceived social support & -0.16 & 0.10 & -1.72 \\
$\quad$ Conflict exposure X Perceived social support & -0.05 & 0.03 & -1.51 \\
\hline B: First-order beliefs (i.e., support for coronavirus & & & \\
measures) & & & \\
Intercept & 0.11 & 0.04 & 0.30 \\
$\quad$ Pandemic concern & 0.28 & 0.04 & $7.14^{* * *}$ \\
$\quad$ Conflict exposure & -0.03 & 0.02 & $-1.97^{*}$ \\
Pandemic concern X Conflict exposure & 0.00 & 0.01 & 0.17 \\
\hline
\end{tabular}

${ }^{*} p<.05 ;{ }^{* *} p<.01 ; * * * p<.001$

Taken together, the model suggests that those concerned about the pandemic support Covid-19 measures and believe others' also support such measures. However, conflict exposure is associated with reduced support for Covid-19 measure. Concern about the pandemic on first- and second-order beliefs does not change as a function of individuals' conflict exposure. In fact, any support for Covid-19 measures is independently driven by individual's concern about the pandemic, irrespective of conflict exposure. However, it is important to recognise that these associations are small. In general, conflict exposure is high among respondents and this is associated with less support for Covid-19 measures, irrespective of concern about the pandemic. Moreover, perceived social support is associated with reduced stress, but is limited in alleviating the significant psychological burden of conflict. This is not to suggest respondents do not rely on their social network as an active coping strategy, but that the perceived size of their social network does not change the negative consequences of conflict.

\section{Discussion}

Research suggests the Covid-19 pandemic and preventive outbreak measures have significant negative welfare effects for communities, with reported rises in population-level stress, 
anxiety and depression reported globally (Brooks et al, 2020; Lades et al, 2020; Wang, et al, 2020). However, these negative psychological symptoms do not emerge for all countries affected by Covid19 (Atalan, 2020), highlighting a need to better understand the range of experiences. The experience of individuals in conflict afflicted western Libya potentially diverges from the global average and warrants investigation. The Covid-19 pandemic unfolds amidst conflict in the region, providing a unique opportunity to examine the sensitivity of individuals to Covid-19 within the context of a preexisting and immediate crisis.

The aim of the current research was to explore the effects of Covid-19 for individuals living under pre-existing crisis conditions, and to understand the additive effect, if any, Covid-19 has on the psychological impact of conflict and citizens' coping strategies. This discussion will address the four research questions in turn, alongside considerations of potential limitations and avenues for future investigation. Following this, strategy recommendations are presented.

\section{People hold normative beliefs that citizens' and the government response is insufficient, but show limited support for Covid-19 measures}

Cross-cultural data suggests there are strong normative beliefs about Covid-19 measures to curb the outbreak of Covid-19, but that the response by citizens' and governments have been insufficient (Fetzer, et al, 2020). In western Libya, these beliefs are not held to the same extent. Compared to a global average reported by Fetzer et al (2020), citizens of western Libya show comparable support for those measures that curb transmission of the virus through direct contact between individuals (i.e., cancelling social gatherings and avoiding shaking hands with other), but far fewer support measures likely to disrupt access to goods and services (i.e., the closure of nonessential shops) and (social) mobility (i.e., a curfew) ${ }^{2}$. In addition, citizens underestimate the extent to which their fellow citizens support the implementation of Covid-19 measures and believe the public response to be insufficient. In fact, the difference between first- and second-order beliefs was considerably larger in residents of western Libya, compared to a global average (see Fetzer, et al, 2020). Moreover, first- but not second-order beliefs predict citizens' evaluations of the pandemic as a substantiative cause for concern. These findings add to our understanding of global perceptions of Covid-19 by suggesting that there are differences in people's experience of the pandemic and consequently, variations in beliefs about Covid-19 measures.

As predicted, a higher proportion of residents of western Libya believe their government response to the pandemic has been insufficient and this predicts their evaluation of Covid-19 as a

\footnotetext{
2 In contrast to the $75.03 \%$ reported by Fetzer et al (2020), just over half (57\%) of respondents from western Libya support the closure of non-essential shops and implementation of a curfew (54\% vs. $74.88 \%$ ).
} 
concern for them ${ }^{3}$. While it is important to recognise the limited explanatory power of the model, these findings are not surprising given the country's socio-political and economic climate. At the onset of the pandemic, the conflict in western Libya saw the targeting of healthcare facilities, cuts to basic services and a divided and corrupt political response to Covid-19 (Khalifa, 2020). An evaluation of the preparedness of Libya's healthcare system found an alarming lack of resources for detecting and treating Covid-19 (ElHadi, Msherghi, Alkeelani, et al, 2020). Strict preventive measures were imposed in western Libya early on (e.g., curfews, fines for flouting, etc.), but these allowed forces to operate with greater impunity (Khalifa, 2020) which worsened the humanitarian situation. Reduced public support for measures is likely a consequence of this dynamic. More specifically, the strained socio-political and economic situation is likely to explain the exaggerated beliefs that the public and government response is insufficient, as compared to global trends.

Research shows endorsement and compliance with Covid-19 measures is not normative. Data from Germany shows that while respondents endorsed and complied with a national lockdown policy at the onset of the pandemic (23 March 2020), extensions or intensification of a lockdown (i.e., measures with a large temporal distance) were not viewed favourably (Gollwitzer, Platzer, Zwarg \& Göritz, 2020). This is predicted by the Construal Level Theory, which proposes that socially, spatially or temporally distant events are construed on a high level, while close events are construed on a low level (Liberman \& Trope, 1998). If physical distancing measures disrupt central human needs, Gollwitzer et al (2020) argue being forced to not meet with members of one's social network for an extended time is perceived as particularly aversive. From a theoretical perspective, a construal level framework could explain the current findings, though an understanding of the temporal dimension of citizens' perception of both crises, Covid-19 and the conflict, is necessary.

Conceptually, Covid-19 and distancing measures may be perceived as psychologically and temporally distant in comparison to the immediate threats imposed by conflict. This perception may be akin to the perceived distance often reported in relation to climate change (see Spence, Poortinga \& Pidgeon, 2012; Pahl, Sheppard, Boomsma \& Groves, 2014; Sing, Zwickle, Bruskotter \& Wilson, 2017). Consequently, lack of support for Covid-19 measures in western Libya (specifically closing non-essential shops and introducing a curfew) may occur. Individuals construe the restrictions on a high level, in light of the immediate threats posed by conflict, by considering the negative impact of distancing on their already limited yet essential (social) mobility. While the construal of Covid-19 measures was not empirically assessed in this study, examining the temporal

\footnotetext{
${ }^{3}$ Compared to global averages reported by Fetzer et al (2020) a higher proportion of citizens of western Libya believe the government response to be insufficient ( $81 \%$ vs. $42 \%$ ), do not trust the government to take care of citizens (68\% vs. $36 \%$ ) and believe the government has not been truthful about Covid-19 (55\% vs. 34\%).
} 
dimensions of people's perceptions of the pandemic in light of a pre-existing threat, offers an interesting avenue for future research.

Population stress is predicted by the perceived inability to cope with the conflict and everyday life

Residents of western Libya living under high-stress conditions of armed conflict and Covid-19 report a high level of behavioural, emotional and physical stress symptoms. As expected, citizens' perceived inability to cope with everyday life and the conflict, and to be emotionally strong predict higher overall stress, while a perceived ability to cope with Covid-19 does not. This observation is not unexpected given the social, economic and political consequences of the war on citizens' daily lives. Before the most recent war in 2019, a Gallup report found a considerable proportion of Libyans felt the economy was getting worse (52\%) and did not have enough money to buy food (43\%) or pay for adequate housing (37\%) (Berrached \& Reinhart, 2019). While this data was collected in 2018, the most recent armed conflict in western Libya has likely compounded the effects of economic decline and instability for residents, which takes a psychological toll.

The current findings are also in line with research on the impact of Covid-19 on frontline healthcare workers in Libya. Recall, while the stigma of caring for Covid-19 patients was associated psychological distress, exposure to Covid-19 was not. Instead, living in a conflict zone was correlated with heightened depression and anxiety symptoms (Elhadi, Msherghi, et al, 2020). In addition, Libyan medical students showed a higher prevalence of anxiety associated with conflict-specific factors, but not Covid-19 related factors (Elhadi, Buzreg, et al, 2020). The current findings extend these observations to the general population by suggesting the conflict transcends daily life and psychological wellbeing, resulting in higher population-level stress.

Despite the lack of trust in the government to adequately respond to Covid-19, the pandemic seems to have little additive effect on the psychological condition of the population already managing the impact of armed conflict. This finding supports the theoretical justification for citizens' limited endorsement of Covid-19 measures outlined above. That is, citizens show limited support for Covid-19 measures because they disrupt social mobility and limit access to essential goods and services. Citizens rely on these tools to mitigate or cope with the daily social and economic consequences of conflict, construed on a low level, in comparison to Covid-19. Understanding the little additive effect Covid-19 has on the psychological condition of the population in western Libya has significant policy implications for both national and international conflict resolution and pandemic response efforts. This is considered further in the recommendations. 


\section{Citizens' draw on social capital, but do not have effective personal coping mechanisms to deal with the psychological impact of conflict}

To a minor degree, perceived ability to cope with the pandemic independently reduces stress for those concerned about Covid-19. However, as discussed above, negative pandemic-related CSE is not a predictor of population level stress. As such, the following discussion centres on citizens' perceived CSE and social support as coping strategies to deal with the psychological impact of the conflict specifically.

Overall, exposure to conflict has a profound negative psychological impact on the population. The findings reveal conflict exposure as the largest independent contributor to population-level stress in western Libya. As stated above, negative conflict-related CSE is a predictor of stress. However, the negative psychological impact of conflict exposure does not change as a function of conflicted-related CSE. While conflict-related CSE independently relates to a small reduction in stress, it seems the psychological impact of conflict outweighs any perceived ability to cope with the consequences of armed conflict. This suggests residents of western Libya do not have adequate personal coping strategies in the form of perceived CSE to deal with the conflict. Given the socio-political and economic situation described above, it is not illogical to argue that there is little, if any, variation in the populations' perceived CSE, which would potentially explain the absence of a moderating effect on stress.

Armed conflict is a significant resource depleting experience: citizen exposed to armed conflict perceive a greater threat to their resources. According to COR theory (Hobfoll, 1989), to conserve resources in high stress situations, individuals expend personal resources such as CSE. Recall, belief that one has control over an aversive event protects from psychological distress by influencing perception and cognitive processing of the threat (Benight \& Bandura, 2004). However, such resource expenditure is only beneficial if it is not outweighed by the psychological burden of the aversive event. The current findings suggest that for citizens of western Libya, conflict exposure depletes individuals' resources beyond any benefit of expending personal resources to cope. This is further supported by the finding that conflict exposure seems to overshadow any benefit of conflictrelated CSE on population level stress. This is in line with Snyders et al's (2020) observation that resource loss predicts stress outcomes beyond the contribution of demographics, relocation experiences and daily stressors (Snyder, et al, 2020) during chronic armed conflict. Further research should employ (quasi-)experimental methods to better understand the role and determinants of perceived CSE (i.e., low vs. high CSE) in armed conflict. 
In the absence of perceived CSE, citizens may turn to social support networks to mitigate the psychological effects of conflict exposure. Indeed, greater perceived social support is associated with reduced overall stress and individual stress outcomes (behavioural, emotional and physical) for citizens of western Libya, which replicates previous findings (e.g., Wang, et al, 2014; Hall, et al, 2014). However, perceived social support is limited in alleviating the significant psychological burden of conflict (i.e., conflict-related stress does not change as a function of perceived social support). Initially, this seems surprising given citizens' dismissal of Covid-19 measures that limit social mobility. However, citizens report high conflict exposure, and this is associated with their support for preventive Covid-19 measures. If perceived social support is considered an interpersonal resource to buffer the psychological effects of aversive events (Cohen \& Wills, 1985), the findings suggest that the size of the social network does not alter this effect. This suggests citizens rely on social capital to manage the negative consequences of conflict, but the perceived size of their social network does not alter the psychological effect of conflict.

It is possible to speculate that the socio-political and economic impact of armed conflict is beyond the benefits afforded by merely increasing one's social network. Reduced access to basic services and amenities and risk of displacement across the region may create a feeling of shared experience. Accessing one's social network (i.e., perceived social support) may be a relatively effective psychological buffer against the negative psychological impact of armed conflict for individuals in some respects, but limited in others. Nonetheless, social networks are one element of social capital found to mediate the impact of armed conflict on people's vulnerabilities (Lomorro, et al, 2004). As such, the role of social capital and how it relates to efforts to mitigate the consequences of conflict in western Libya requires further investigation. This is discussed further in relation to the potential limitations of the current research and emerging avenues for future research.

\section{Limitations and Future Research}

This discussion first outlines methodological limitations and the sensitivity of the measures, before considering the impact of the current socio-political and economic context of western Libya on the findings.

\section{Methodological limitations}

Recruiting through online survey dissemination and snowballing could induce selection bias, with the survey attracting participants who were more concerned about the Covid-19 pandemic than other residents. Given the challenges of conducting field research in Libya, it is outside the scope of the research to utilise truly randomised sampling. Nonetheless, a consistent observation 
was the larger effect of conflict exposure on outcome measures compared to concern about the pandemic.

It is important to also acknowledge that the research only concerns beliefs and perceptions of Covid-19, and the impact of conflict in one region of Libya. The decision to focus on western Libya was a result of the most recent escalation in armed conflict centred in the region. Nonetheless, practitioners and policymakers working on conflict resolution, political stability and the Covid-19 response in Libya would benefit from understanding the country's regional variations in terms of the impact of conflict and Covid-19 to develop evidence-based approaches, in light of the socio-political and economic context.

\section{Measure Sensitivity}

While the current study did capture citizens' beliefs and perceptions about Covid-19 measures, behaviour was not assessed. Fetzer et al (2020) found that respondents' own belief and their perceptions of others' beliefs predicted their tendency to engage in protective behaviours. Behaviours were not measured in the current study. Given the finding that citizens of western Libya are not strong supporters of Covid-19 measures, an understanding of the degree to which residents engage in protective behaviours (e.g., wearing a mask, staying home) would be insightful for Covid19 response planning. Along the same line, it is also important to understand citizens' beliefs and perceptions about Covid-19 vaccines and the likelihood of uptake. If conflict exposure is related to lack of support for Covid-19 measures, a strong vaccine response programme will be necessarily to alleviate strain on the healthcare system. Therefore, understanding citizens' perceptions of and likely behaviours towards the vaccine is hugely important for promoting large scale vaccine uptake (this is discussed further in relation to implication and recommendations).

Moreover, the measure of conflict exposure was a composite variable of four conflictsensitive items of the CCAQ. It is not possible to determine the reliability of this composite item as a measure of individual conflict exposure. As such, a more sensitive and reliable measure of individual response variation to prolonged conflict should be employed. A review of the reliability and predictive validity of measures for cumulative trauma exposure for individuals affected by conflict found trauma measures to be a reliable indicator of lifetime PTSD risk prediction (Wilker, et al, 2015). However, these measures focus on PTSD and mental health outcomes (e.g., anxiety and depression), with little consideration of other dimensions of conflict exposure, including cognitive, emotional, behavioural, social and economic factors. For instance, research shows that exposure to conflict moderates the relationships between perceived intergroup threat and wellbeing and therefore, devising a more sensitive measure of individual conflict exposure has implications for 
research and policy in political-conflict settings (Schmid \& Muldon, 2015). As such, a culturally sensitive and quantified measure of conflict exposure for citizens beyond PTSD is important for domestic and international response efforts to mitigate the impact of conflict in Libya.

Similarly, the findings raise the question of whether perceived social support is a sensitivity measure of social capital. Perceived social support was associated with the inverse of stress but did not moderate the effect of conflict exposure. Evidence suggests citizens affected by armed conflict harness coping abilities (e.g., self-esteem) and resources such as social capital to rebuild resilience (Lomorro, et al, 2004). Understanding individual and community level resilience and adaptability in relation to coping abilities and resources has significant policy implications for understanding and mitigating the effects of conflict in Libya. Resilience - competence or effective coping in response to risk (Mayordomo, et al, 2016) - and the ability to adapt to adversity are functions of agency alongside coping resources. For instance, internally displaced people in Pakistan show a positive association between resilience and the inverse of stress, anxiety and depression (Mujeeb \& Zubair, 2012). Likewise, young people affected by war show high resilience, explained by agency, parental support and community acceptance (Bosqui \& Marshoud, 2018). However, resilience varies considerably across contexts (e.g., gender, and socio-cultural and political circumstances) and between individuals and communities (Ahmed, et al, 2004), with ecological factors including cultural background and experience influencing the development of resilience (Clauss-Ehlers, 2008). Yet, resilience remains under-researched (Ahmed, et al, 2004; Lomorro, et al, 2004) particularly in the context of armed conflict. Understanding resilience as more than the absence of PTSD, but as an outcome related to agency and coping resources is important for evidence-based policy and practice (Almedom \& Glandom, 2007). Future research would benefit from exploring these factors of coping and agency in conflicted afflicted Libya.

\section{Libya's Fluid Socio-Political Climate}

It is important to frame the current findings within the changing socio-political context. At the start of the data collection period (5 June 2020) Libya had over 200 confirmed cases of Covid-19, rising to almost 3000 at the end of the data collection period (19 July 2020). These figures were relatively low in comparison to global numbers, likely due to limited travel across borders. Libya has since experienced a rapid increase in cases, currently with over 130,000 confirmed cases and over 2000 deaths (WHO Covid-19 disease dynamic infographic dashboard for Libya, 23 Feb 2021).

Currently, active conflict is paused, and Libya appears to have moved to peacebuilding processes and political reconciliation, which could have implications for the application of current findings. Despite this, the country remains in a state of 'quiet civil war'. A recent health sector review 
revealed the threat of large-scale hostilities and foreign armed groups remains present and the population continues to face many of the insecurities and risks associated with the conflict, including limited resource access, monitory liquidity issues, and political and economic instability. As of January 2021, Libya remains a category 2 emergency country with 1.3 million people in need of humanitarian assistance (Health Cluster, Jan 2021). As such, the current findings with regards to the impact of armed conflict and beliefs and perceptions of Covid-19 remains relevant. And it highlights the necessity for long-term monitoring and observation of the socio-political and economic climate on population level wellbeing and beliefs and perceptions of and behaviours towards Covid-19 and vaccine programmes in Libya.

\section{Recommendations}

The current study illustrates the poignant notion that globally, citizens' experience of Covid19 is not normative. In the context of armed conflict, the current findings show that Covid-19 is not perceived as an immediate and existential threat. Citizens affected by armed conflict do not support Covid-19 measures to the same degree as citizens in stable states and the pandemic has little additive effect on citizens' negative psychological wellbeing beyond the effects of conflict. It is prudent to consider variations in the global experience of Covid-19 and encourage governments to devise tailored pandemic response policies, informed by the behaviours and perceptions of their citizens. As a result of the current findings, the author makes the following recommendations regarding the response to Covid-19 in western Libya.

First, the government in Libya should prioritise a swift Covid-19 strategy to establish public trust in the government's ability to handle the outbreak. The belief that the government response has been insufficient was a significant predictor of citizen's concern about the pandemic. While concern about Covid-19 is not a significant contributor to public stress, for those that are concerned it is important the government is perceived as acting sufficiently as a first step to containing the outbreak. Recent reports suggest government corruption involving Covid-19 funds results in shortfalls and reliance on humanitarian organisations (CCHN, Nov 2020). This does little to improve the public perception of the government response.

Second, the government should actively take the public's limited endorsement of Covid-19 measures into account. It is possible the reduced public support for Covid-19 measures is a result of individuals construing them as disruptive to their already limited but essential mobility in light of the threat of conflict. In line with this, observers argue that while implementing distancing measures such as curfews could contribute to lower Covid-19 cases, it does not consider the humanitarian impact on families struggling with the consequences of conflict (Khalifa, 2020). In taking the public's 
lack of endorsement for Covid-19 measures, the government response should be to prioritise a vaccine roll-out programme and begin early dissemination of information to promote vaccine uptake and dispel vaccine misinformation in Libya. Despite the efficacy and public-health benefits of the Covid-19 vaccines, global concerns around vaccine safety are high (Tseng, 2020). Recent data shows only $66 \%$ of citizens in Libya would accept or probably accept a vaccine (IHME, Mar 2021), suggesting vaccine perception warrants urgent investigation. If the government is to offer an efficient Covid-19 response that acknowledges the inability of the public to adhere to distancing measures, it should: 1 ) prioritise granting regulatory approval of vaccine use and release funds to purchase vaccines, 2) deliver a coordinated information campaign to promote vaccine uptake and dispel anti-vaccine concerns, and 3) encourage the country's Covid-19 National Coordination Committee to publish an efficient timetable by which to vaccinate high-risk members of the population, including refugees and internally displaced people.

Finally, there is little if any data available on the status of Libya's vaccine roll-out programme (OWID, Feb 2021) and current projections suggest Libya will not vaccinate its population until early 2023 (The Economist Intelligence Unit, Jan 2021), which could have negative consequences both domestically and internationally. Given the risk of vaccine-resistant strains and Libya's status as a port for European migration, it is in the interest of European countries and the international community to provide support to the conflict afflicted nation to begin vaccine roll-out. At the current time, with no vaccine programme underway, the government should work to alleviate or mitigate the circumstances preventing the public from adhering to distancing measures by providing some level of economic security. Recall, recent data from Gallup shows Libyan citizens are unable to cope with the economic fallout of conflict and political unrest, with many reporting little money to buy food and pay for adequate housing (Berrached \& Reinhart, 2019).

\section{Conclusions}

The current findings show the negative psychological impact of the pandemic is not consistent cross-culturally. Adding to global data, citizens of western Libya share the normative belief that governments have been insufficient in their response to the outbreak but diverge from global trends by showing limited support for Covid-19 preventive measures. This may be predicted by the Construal Level Theory as citizens construe such measures on a high level by considering the negative impact on their already limited but essential mobility. Indeed, population-level stress is predicted by the inability to cope with the conflict and everyday life and to be emotionally strong.

Continuity of armed conflict has compounded the already dire social and economic conditions, with Covid-19 having little additive effect on citizens' psychological wellbeing. Taking the 
individual as the level of analysis, citizens do not have effective personal coping mechanisms to deal with the impact of armed conflict. Using a COR framework, expending personal resources, in the form of coping-self efficacy, does not mitigate the impact of conflict on stress. However, drawing on social capital by means of perceived social support may go some way in alleviating some of the impact of armed conflict, though the socio-political and economic consequences may limit this.

Numerous questions remain, particularly concerning the different aspects of resource expenditure that contribute to wellbeing in the context of armed conflict and citizens' response to the Covid-19 vaccine. The findings have practical and strategy implications for both the government and international Covid-19 response in Libya.

\section{References}

Abdel-Khalek, A. M. (2007). Assessment of Intrinsic Religiosity with a Single-Item Measure in a Sample of Arab Musims. Journal of Muslim Mental Health, 2, 211-215. DOI: 
Alkhamees, A. A., Alrashed, S. A., Alzunaydi, A. A., Almohimeed, A. S., \& Aljohani, M. S. (2020). The psychological impact of COVID-19 pandemic on the general population of Saudi Arabia. Comprehensive psychiatry, 102, 152192

Almedom, A. M., \& Glandon, D. (2007). Resilience is not the absence of PTSD any more than health is the absence of disease. Journal of loss and Trauma, 12(2), 127-143

Atalan, A. (2020). Is the lockdown important to prevent the COVID-19 pandemic? Effects on psychology, environment and economy-perspective. Annals of medicine and surgery, 56, 3842

Azur, M. J., Stuart, E. A., Frangakis, C., \& Leaf, P. J. (2011). Multiple imputation by chained equations: what is it and how does it work? International journal of methods in psychiatric research, 20(1), 40-49

Badi, E. (2020). Covid-19 and Libya's Tragedy of the Commons. In Mezran, K., \& Perteghella, A. (Eds.), The Politics of Pandemics: Evolving Regime-Opposition Dynamics in the MENA Region (pp. 13-25). Ledizioni LediPublishing

Benight, C. C., Swift, E., Sanger, J., Smith, A., \& Zeppelin, D. (1999). Coping self-efficacy as a mediator of distress following a natural disaster. Journal of Applied Social Psychology, 29(12), 24432464

Benight, C. C., \& Bandura, A. (2004). Social cognitive theory of posttraumatic recovery: The role of perceived self-efficacy. Behaviour research and therapy, 42(10), 1129-1148

Bennett, D. (2001). How can I deal with missing data in my study? Australian and New Zealand Journal of Public Health, 25(5), 464-469

Berrached, I., \& Reinhart, R. J., (2019). Life in Libya Getting Worse Before Recent Fighting. Gallup. https://news.gallup.com/poll/257660/life-libya-getting-worse-recent-fighting.aspx

Bosmans, M. W., Komproe, I. H., van Loey, N. E., van der Knaap, L. M., Benight, C. C., \& van der Velden, P. G. (2017). Assessing perceived ability to cope with trauma: A multigroup validity study of a 7-item Coping Self-Efficacy Scale. European Journal of Psychological Assessment, 33(1), 55

Bosqui, T. J., \& Marshoud, B. (2018). Mechanisms of change for interventions aimed at improving the wellbeing, mental health and resilience of children and adolescents affected by war and armed conflict: a systematic review of reviews. Conflict and health, 12(1), 1-17. 
Bredan, A., \& Bakoush, O. (2021). COVID-19 epidemic in Libya. Libyan Journal of Medicine, 16(1), 1871798

Centre of Competence on Humanitarian Negotiation (CCHN). (2020, Nov). How the COVID-19 Pandemic Has Affected Humanitarian Access in Libya. https://frontlinenegotiations.org/2020/11/how-the-covid-19-pandemic-has-affected-humanitarian-accessin-libya/ visited 23 Feb 2021

Christy, A. (2020, Apr). Libya's Rivalries, Risks \& COVID-19 - Part One. Small War Journal. https://smallwarsjournal.com/jrnl/art/libyas-rivalries-risks-covid-19-part-one

Clauss-Ehlers, C. S. (2008). Sociocultural factors, resilience, and coping: Support for a culturally sensitive measure of resilience. Journal of Applied Developmental Psychology, 29(3), 197-212

Cohen, S., \& Wills, T. A. (1985). Stress, social support, and the buffering hypothesis. Psychological bulletin, 98(2), 310 .

Da'ar, O. B., Haji, M., \& Jradi, H. (2020). Coronavirus Disease 2019 (COVID-19): Potential implications for weak health systems and conflict zones in the Middle East and North Africa region. The International journal of health planning and management, 35(5), 1240-1245

Dong, Y., \& Peng, J. (2013). Principled missing data methods for researchers. SpringerPlus, 2(1), 1-17

Elhadi, M., Msherghi, A., Elgzairi, M., Alhashimi, A., Bouhuwaish, A., Biala, M., ... \& Albakoush, A. (2020). Psychological status of healthcare workers during the civil war and COVID-19 pandemic: A cross-sectional study. Journal of psychosomatic research, 137, 110221

Elhadi, M., Buzreg, A., Bouhuwaish, A., Khaled, A., Alhadi, A., Msherghi, A., ... \& Khaled, A. (2020). Psychological impact of the civil war and COVID-19 on Libyan medical students: a crosssectional study. Frontiers in Psychology, 11

Elhadi, M., Msherghi, A., Alkeelani, M., Alsuyihili, A., Khaled, A., Buzreg, A., ... \& Alghanai, E. (2020). Concerns for low-resource countries, with under-prepared intensive care units, facing the COVID-19 pandemic. Infection, disease \& health, 25(4), 227-232

Fetzer, et al, (2020). Perceptions of an Insufficient Government Response at the Onset of the COVID19 Pandemic are Associated with Lower Mental Well-Being. PsyArXiv https://psyarxiv.com/3kfmh

Gollwitzer, M., Platzer, C., Zwarg, C., \& Göritz, A. S. (2020). Public acceptance of Covid-19 lockdown scenarios. International Journal of Psychology. https://doi.org/10.1002/ijop.12721 
Grover, S., Sahoo, S., Mehra, A., Avasthi, A., Tripathi, A., Subramanyan, A., ... \& Reddy, Y. J. (2020). Psychological impact of COVID-19 lockdown: An online survey from India. Indian Journal of Psychiatry, 62(4), 354

Hale, T., Petherick, A., Phillips, T., \& Webster, S. (2020). Variation in government responses to COVID-19. Version 4.0. Blavatnik School of Government Working Paper, April 7, 2020 https://www.bsg.ox.ac.uk/sites/default/files/2020-04/BSG-WP-2020-031-v4.0 0.pdf

Hobfoll, S. E. (1989). Conservation of resources: A new attempt at conceptualizing stress. American psychologist, 44(3), 513

Hutchinson, J. C., Sherman, T., Martinovic, N., \& Tenenbaum, G. (2008). The effect of manipulated self-efficacy on perceived and sustained effort. Journal of Applied Sport Psychology, 20(4), 457-472.

Institute for Health Metrics and Evaluation (IHME). (2021, Mar). COVID-19 Results Briefing: Libya. http://www.healthdata.org/sites/default/files/covid briefs/147 briefing Libya.pdf visited 15 March 2021

International Crisis Group. (April 2020). Global Ceasefire Call Deserves UN Security Council's Full Support. Retrieved from https://www.crisisgroup.org/global/global-ceasefire-call-deservesun-security-councils-full-support

Kim, H. S., Sherman, D. K., \& Taylor, S. E. (2008). Culture and social support. American psychologist, 63(6), 518

Khalifa, A. (2020, April). Conflict and coronavirus - Libyan women pay higher price. Qantara.de. Retrieved from https://en.qantara.de/content/covid-19-pandemic-in-libya-conflict-andcoronavirus-libyan-women-pay-the-higher-price

Lahlou, S. A. "CCAQ: A shared, Creative Commons Crisis Coping Assessment Questionnaire". World Pandemic Research Network. WPRN-413152, 2020-04-12 at 09h35 (GMT):

\section{https://wprn.org/item/413152}

Liberman, N., \& Trope, Y. (1998). The role of feasibility and desirability considerations in near and distant future decisions: A test of temporal construal theory. Journal of personality and social psychology, 75(1), 5 
Lomorro, O., Okuonzi, S., Silva, K. T., Alvarez-Castillo, F., Atuyambe, L., \& Chabikuli, N. (2006). Why some survive: coping, resilience and social capital in armed conflict. African safety promotion, 4(2), 78-87

Mayordomo, T., Viguer, P., Sales, A., Satorres, E., \& Meléndez, J. C. (2016). Resilience and coping as predictors of well-being in adults. The Journal of Psychology, 150(7), 809-821

Mujeeb, A., \& Zubair, A. (2012). Resilience, stress, anxiety and depression among internally displaced persons affected by armed conflict. Pakistan journal of social and clinical psychology, 9(3), 20-26

O'Keeffe, A. G., Farewell, D. M., Tom, B. D., \& Farewell, V. T. (2016). Multiple imputation of missing composite outcomes in longitudinal data. Statistics in biosciences, 8(2), 310-332

Our World in Data. (2021, Feb 23). Statistics and Research: Coronavirus (COVID-19) Vaccinations. https://ourworldindata.org/covid-vaccinations

Pahl, S., Sheppard, S., Boomsma, C., \& Groves, C. (2014). Perceptions of time in relation to climate change. Wiley Interdisciplinary Reviews: Climate Change, 5(3), 375-388

Pearson, L. I., \& Schooler, C. (1978). The Structure of Coping. National Institute of Mental Health, 19, $2-21$

Rodríguez-Rey, R., Garrido-Hernansaiz, H., \& Collado, S. (2020). Psychological impact of COVID-19 in Spain: Early data report. Psychological Trauma: Theory, Research, Practice, and Policy, 12(5), 550

Rossi, R., Socci, V., Talevi, D., Mensi, S., Niolu, C., Pacitti, F., ... \& Di Lorenzo, G. (2020). COVID-19 pandemic and lockdown measures impact on mental health among the general population in Italy. Frontiers in psychiatry, 11, 790

Schmid, K., \& Muldoon, O. T. (2015). Perceived threat, social identification, and psychological wellbeing: The effects of political conflict exposure. Political Psychology, 36(1), 75-92.

Serafini, G., Parmigiani, B., Amerio, A., Aguglia, A., Sher, L., \& Amore, M. (2020). The psychological impact of COVID-19 on the mental health in the general population. QJM: An International Journal of Medicine, 113(8), 531-537

Setti, I., van der Velden, P. G., Sommovigo, V., Ferretti, M. S., Giorgi, G., O'Shea, D., \& Argentero, P. (2018). Well-being and functioning at work following thefts and robberies: A comparative study. Frontiers in psychology, 9, 168 
Sheehy-Skeffington, J. (2019) Inequality from the bottom up: toward a "psychological shift" model of decision-making under socioeconomic threat. In: The Social Psychology of Inequality. Springer International Publishing, pp. 213-231. ISBN 9783030288556

Sheehy-Skeffington, J. (2020) The effects of low socioeconomic status on decision-making processes: power, status and hierarchy. Current Opinion in Psychology, 33, 183-188

Singh, A. S., Zwickle, A., Bruskotter, J. T., \& Wilson, R. (2017). The perceived psychological distance of climate change impacts and its influence on support for adaptation policy. Environmental Science \& Policy, 73, 93-99

Snyder, J. D., Boan, D., Aten, J. D., Davis, E. B., Van Grinsven, L., Liu, T., \& Worthington Jr, E. L. (2020). Resource Loss and Stress Outcomes in a Setting of Chronic Conflict: The Conservation of Resources Theory in the Eastern Congo. Journal of traumatic stress, 33(3), 227-237

Spence, A., Poortinga, W., \& Pidgeon, N. (2012). The psychological distance of climate change. Risk Analysis: An International Journal, 32(6), 957-972

Tan, J. C. (2015). probemod: Statistical Tools for Probing Moderation Effects. R package version 0.2.1. https://CRAN.R-project.org/package=probemod

\section{https://CRAN.R-project.org/package=probemod}

Tee, M. L., Tee, C. A., Anlacan, J. P., Aligam, K. J. G., Reyes, P. W. C., Kuruchittham, V., \& Ho, R. C. (2020). Psychological impact of COVID-19 pandemic in the Philippines. Journal of affective disorders, 277, 379-391

The Economist Intelligence Unit. (2021, Jan 27). More than 85 poor countries will not have widespread access to coronavirus vaccines before 2023. https://www.eiu.com/n/85-poorcountries-will-not-have-access-to-coronavirus-vaccines/

Tsenfg, B. (2020, Dec 17). Combatting Vaccine Misinformation in the Age of the Internet. Tony Blair Institute for Global Change. https://institute.global/policy/combatting-vaccinemisinformation-age-internet

Van Buuren, S., \& Groothuis-Oudshroorn, K. (2001). mice: Multivariate Imputation by Chained Equation. Journal of Statical Software, 45(3), 1-68

Wang, X., Cai, L., Qian, J., \& Peng, J. (2014). Social support moderates stress effects on depression. International journal of mental health systems, 8(1), 1-5 
Wang, Y., Di, Y., Ye, J., \& Wei, W. (2020). Study on the public psychological states and its related factors during the outbreak of coronavirus disease 2019 (COVID-19) in some regions of China. Psychology, Health \& Medicine. DOI: 10.1080/13548506.2020.1746817

Wilker, S., Pfeiffer, A., Kolassa, S., Koslowski, D., Elbert, T., \& Kolassa, I. T. (2015). How to quantify exposure to traumatic stress? Reliability and predictive validity of measures for cumulative trauma exposure in a post-conflict population. European

\section{Acknowledgements}

The author thanks Dr Jet Sanders, Dr Jennifer Sheehy-Skeffington and Prof Saadi Lahlou for their insights into research and the LSE Covid-19 Behavioural Science working group for their feedback. In addition, thanks to Marwa Ben Khalifa and Marouane Oueslati for translations of the survey and instruments and thank you to Abdulraouf Tresh and Dr Laura Smith for their edits to this manuscript. 